\title{
BULLYING E AS RELAÇÕES DE GÊNERO PRESENTES NA ESCOLA
}

\author{
BULLYING Y LAS RELACIONES DE GÉNERO PRESENTES EN LA ESCUELA
}

BULLYING AND GENDER RELATIONS AT SCHOOL

Michele Ziegler de Mattos ${ }^{*}$ Angelita Alice Jaeger ${ }^{*}$

\section{Palavras-chave} Bullying. Identidade de gênero. Comportamento. Ensino fundamental e médio.

\section{Keywords:} Bullying. Gender identity. Behavior. Education, primary and secondary.

Palabras clave Acoso escolar. Identidad de género. Conducta. Educación primaria y secundaria.
Resumo: Analisamos as interfaces entre o bullying e as relações de gênero no contexto escolar, identificando essa manifestação entre 95 meninos e meninas de 4⿳亠丷a a 8aㅡ séries de uma escola pública. A triangulação dos dados foi constituída por um questionário respondido pelos/as estudantes, observações do contexto escolar e conversas informais com a equipe diretiva e alunos/as. Os resultados apontam que o bullying se destaca através da agressão verbal e seus protagonistas são, em sua maioria, do sexo masculino. As representações de gênero que permeiam o cotidiano dos estudantes evidenciam que meninos e meninas são educados de modos diferentes.

Abstract: The aim of this study was to analyze the interfaces between bullying and gender relations in the school context. We found it in 95 boys and girls from $4^{\text {th }}$ to $8^{\text {th }}$ grade in a public school. Data triangulation consisted of a questionnaire answered by students, school context observations and informal conversations with management staff and students. Results showed that bullying happens through verbal aggression and its protagonists are mostly male. Gender representations that pervade the daily lives of students show that boys and girls are educated in different ways.

Resumen: Analizamos las interfaces entre el bullying y las relaciones de género en el contexto escolar, identificando esa manifestación entre 95 chicos y chicas de $4^{\circ}$ a $8^{\circ}$ años de una escuela pública. La triangulación de los datos fue constituida por un cuestionario contestado por los/las estudiantes, observaciones del contexto de la escuela y charlas informales con el equipo directivo y alumnos/as. Los resultados señalan que el bullying se destaca a través de la agresión verbal y que sus protagonistas son, en su mayoría, del sexo masculino. Las representaciones de género que permean el cotidiano de los estudiantes evidenció que chicos y chicas son educados de modos diferentes.
Universidade Federal de Santa Maria. Santa Maria, RS, Brasil.

E-mail: mimicefd@gmail.com

Recebido em: 19-06-2014

Aprovado em: 22-01-2015

(c) (1) (8) Licence 


\section{CONSIDERAÇÕES INICIAIS}

A cultura da violência atravessa o cotidiano escolar, e suas manifestações aparecem frequentemente em notícias de jornais, televisão, revistas e na internet, apontando o bullying como um problema central nas instituições educativas contemporâneas.

0 bullying se configura em um conjunto de atitudes agressivas, intencionais e repetitivas como, por exemplo, implicância, discriminação e agressões verbais e físicas, sendo praticado tanto por meninos quanto por meninas. Os/as agressores/as apresentam características associadas a um perigoso poder de liderança, que aparece tanto em meninas como em meninos, e que nem sempre é legitimado pela força física, e, sim, via assédio psicológico intenso sobre a vítima. Todavia, configuram-se de maneira diferenciada quando praticado por meninas ou por meninos. Aquelas agem, na maioria das vezes, discretamente, por meio da agressão verbal, com mexericos e intrigas, enquanto que para estes nem sempre é assim, pois necessitam utilizar a força física, como chutes e pontapés (SILVA, 2010) ${ }^{1}$.

As diferenças e peculiaridades nos modos de agir e reagir de meninos e meninas em situações de bullying são efeitos do processo de generificação dos corpos, cujas inscrições são produzidas em diferentes instâncias sociais, entre elas, a escola. Nessa instituição, afirma Louro (2010a), há um investimento em uma pedagogia que educa de modo diferenciado os corpos dos meninos e os corpos das meninas. Para eles, investe-se em uma determinada construção de masculinidade em que os esportes coletivos, as brincadeiras de lutas, o suor, o esforço físico intenso, a competição e uma certa violência consentida não são apenas esperados, como também estimulados entre os meninos; vivências que os encaminham a uma direção, produzindo um certo tipo de garoto. Para as meninas, a escola investe na produção de uma feminilidade referente que as ensina a serem obedientes, ouvintes, delicadas e avessas à agressão, prescrevendo as ginásticas e o voleibol como ingredientes de uma educação que produz um determinado tipo de garota. Além disso, os espaços escolares também são generificados, uma vez que o seu território não é equitativamente partilhado pelos/as estudantes. De acordo com Wenetz, Stigger e Meyer (2013), as brincadeiras são generificadas e sexualizadas e ocupam diferentes espaços no pátio escolar, os quais são disputados, negociados ou impostos. É esperado e é aceito que os garotos ocupem as quadras esportivas e que as garotas brinquem ou fiquem sentadas em grupinhos conversando nos territórios tomados pelos primeiros. Tal distinção interpela os/as estudantes e produz em muitas meninas a recusa na participação em atividades que envolvam maior esforço físico, como é o caso da prática do futebol. Por outro lado, muitas vezes são os próprios meninos que rejeitam a participação das meninas, por acreditarem que elas devem optar pelas práticas corporais e esportivas mais delicadas. Essas desigualdades produzem conflitos quando algumas garotas ousam desrespeitar essas normas e, muitas vezes, resultam em situações de bullying.

O Projeto Pedagógico de Curso e, sobretudo, os/as professores/as que o colocam em funcionamento, precisam deixar de olhar os corpos de meninas e meninos, garotas e garotos apenas a partir da perspectiva biologicista, e tampouco confiar na distinção sexual como justificativa para as diferenças e as desigualdades vividas pelos/as estudantes na escola. Louro (2010b, p. 21) afirma que as representações construídas em torno das características

1 A Cartilha elaborada em 2010 pelo Conselho Nacional de Justiça, de autoria de Ana Beatriz Barbosa Silva, é destinada a professores e profissionais da escola, com o objetivo de alertá-los quanto ao modo de identificação do problema e às formas de prevenção desse fenômeno social. 
sexuais, assim como "aquilo que se diz ou pensa sobre elas que vai constituir, efetivamente, o que é feminino ou masculino em uma dada sociedade e em um dado momento histórico". Nesse sentido, o conceito de gênero que sustenta as análises aqui empreendidas busca:

[...] englobar todas as formas de construção social, cultural e linguística implicadas em processos que diferenciam mulheres e homens, incluindo aqueles processos que produzem seus corpos, distinguindo-os e separando-os como corpos dotados de sexo, gênero e sexualidade. 0 conceito de gênero privilegia, exatamente, 0 exame dos processos de construção e distinções - biológicas, comportamentais ou psíquicas percebidas entre homens e mulheres (MEYER, 2013, p. 16).

Assim, entendemos que diferentes instâncias sociais produzem encaminhamentos nos quais as relações de gênero são construídas polarizando os atributos que marcam os corpos de meninas e meninos, garotas e garotos, mulheres e homens, construindo noções normalizadas de feminilidade e de masculinidade. Nesse sentido, espera-se que as meninas e mulheres sejam sempre as vítimas de violência e os meninos e homens assumam a posição de produtores e reprodutores dessas ações. Todavia, esquece-se que há situações de xingamentos, agressões físicas e mortes entre mulheres. As representações que apenas vitimizam as mulheres são postas em questão quando observamos o elevado número de artefatos culturais que trazem reportagens e imagens nas quais as meninas e garotas são as protagonistas, tanto na posição de agressoras quanto na de vítimas em situações de bullying no contexto escolar.

Facco (2009) afirma que a instituição escolar representa um microuniverso social que se caracteriza pela diversidade social e cultural e, muitas vezes, reproduz padrões de conduta que permeiam as relações sociais fora da escola. Assim, as formas de se relacionar com 0 outro, na escola, refletem as práticas sociais mais amplas.

A partir dessas considerações, esta pesquisa buscou analisar as interfaces entre o bullying e as relações de gênero no contexto escolar, identificando essa manifestação entre meninos e meninas no ensino fundamental em uma escola pública na cidade de Santa Maria-RS. Entendemos que as relações de gênero são atravessadas pelas relações de poder, as quais são disputadas e, amiúde, resultam desiguais quando consideramos o modo como meninos e meninas apropriam-se, utilizam e vivenciam os espaços da escola. Ao compreender como acontece o bullying nesses espaços, também buscamos analisar como as relações sociais se intensificam, principalmente as de gênero. Notamos que a escola ainda encontra dificuldades em abordar o bullying como um problema a ser estudado e debatido por todos/as. Percebemos que a instituição busca a solução do problema, mas, muitas vezes, não sabe como agir, pois faltam meios de reflexão e enfrentamento do bullying. Todavia, conhecer em que situação ele acontece se configura em um momento de diagnóstico da situação que pode impulsionar a comunidade escolar a posicionar o tema no centro das preocupações escolares.

\section{CAMINHOS METODOLÓGICOS}

Essa investigação integra 0 aspecto qualitativo e 0 quantitativo a fim de abordar 0 tema do bullying e as relações de gênero no contexto escolar. Minayo e Sanches (1993, p. 247) destacam que "[...] o estudo quantitativo pode gerar questões para serem aprofundadas qualitativamente, e vice-versa". 
O alvo do estudo constituiu-se de crianças e adolescentes de ambos os sexos, matriculados nas turmas entre $4^{\underline{a}}$ e $8^{\mathrm{a}}$ séries, estudantes do ensino fundamental de uma escola ${ }^{2}$ da rede estadual de Santa Maria-RS. A pesquisa foi realizada com 95 crianças e adolescentes que estudam no turno da manhã, os quais apresentaram o Termo de Consentimento Livre e Esclarecido ${ }^{3}$ assinado pelos pais e/ou responsáveis, consentindo em sua participação. Assim, a amostra final contou com 49 meninas e 46 meninos, com idades que variaram entre dez e 16 anos. Também contamos com a participação de professores e da equipe diretiva da escola (diretora e coordenadora pedagógica).

Os instrumentos para produzir as fontes de pesquisa constituíram-se de observações, conversas informais e aplicação de um questionário. Primeiramente, foram realizados 14 episódios de observações buscando olhar atentamente o contexto do recreio escolar, assim como cinquenta minutos do tempo que 0 antecedia e que o sucedia, em dias intercalados da semana (segunda-feira, quinta-feira e sexta-feira) no decorrer de um mês. Cada observação contabilizou em torno de duas horas de duração. As observações tinham como objetivo captar as ações das crianças durante o recreio escolar que de algum modo caracterizavamse como bullying, como, por exemplo, situações de agressividade em brincadeiras, situações de xingamentos, empurrões, ou seja, percepções acerca da violência nas ações de meninos e meninas. Nesses momentos ainda aconteceram conversas informais com alunos/as e com alguns/mas professores/as e equipe diretiva da escola, sendo realizadas em situações aleatórias. Tanto as observações do contexto escolar quanto as conversas informais com professores/as e equipe diretiva da escola foram minuciosamente registradas em diário de campo.

As fontes produzidas neste primeiro momento indicaram a necessidade de um esclarecimento sobre o bullying, visto que identificamos dúvidas e desconhecimento sobre 0 tema. Assim, realizou-se uma exposição para as turmas do turno da manhã no saguão da escola, em que, após a apresentação, os/as alunos/as retornaram às suas respectivas salas de aula e responderam ao questionário "Violência entre pares", proposto por Freire, Simão e Ferreira (2006). A aplicação iniciou nas turmas de $8^{a}$ série e seguiu em direção decrescente, tendo em vista que alunos/as mais novos/as necessitaram de um tempo maior para o preenchimento do instrumento. As turmas de $4^{a}$ e $5^{\mathrm{a}}$ séries levaram em torno de 40 minutos para respondêlo, enquanto que 6ª $7^{\underline{a}}$ e $8^{\underline{a}}$ séries entre 25 e 30 minutos. Segundo Cervo e Bervian (2002), o questionário é a forma mais usada para coletar dados, pois possibilita medir com melhor exatidão o que se deseja.

As observações do contexto escolar, as conversas informais com a equipe diretiva, professores e estudantes e os resultados obtidos com o questionário nos permitiu uma triangulação de fontes de pesquisa, o que possibilitou uma visão ampla da complexidade do estudo. Stake (2011, p. 138) aponta que "[...] os pesquisadores triangulam suas evidências [...] para chegar aos significados corretos, para ter mais confiança de que a evidência é forte, eles desenvolvem diversas práticas chamadas de triangulação". Assim, os resultados e discussões serão apresentados por meio de um registro percentual dos dados obtidos no questionário,

2 É uma escola de periferia da cidade que recebe alunos/as que têm uma condição socioeconômica baixa, vivem no bairro e arredores e, sobretudo, são moradores/as de uma área irregular, invadida há alguns anos, situada próxima do estabelecimento de ensino. A escola disponibiliza oito salas de aula, uma quadra aberta, um saguão amplo coberto, um corredor para a prática de atletismo e uma pracinha para as crianças. A equipe escolar é composta por 24 professores e 121 estudantes no turno da manhã, turno em que foram realizadas as coletas. 
acompanhados de fragmentos retirados do inventário das observações e das conversas informais realizadas na escola. A triangulação desse material empírico e o diálogo com 0 referencial teórico resultaram nas análises produzidas com vistas a responder aos objetivos dessa investigação.

\title{
3 A ESCOLA E O BULLYING
}

O bullying tornou-se um problema mundial e, atualmente, os profissionais envolvidos na área da educação estão preocupados em reduzir o comportamento violento de jovens do mundo todo. Partindo das respostas obtidas com o questionário, evidenciamos que a grande maioria de estudantes (79\%) afirmou que a escola é um ambiente seguro, organizado e bom para conviver com os amigos. Todavia, um pequeno número (9\%) apontou que poderia ter menor incidência de brigas no seu contexto. Tomando o sexo dos estudantes como elemento de análise, destacamos que $6 \%$ das meninas disseram que as brigas poderiam diminuir, enquanto que os meninos representaram apenas a metade (3\%) daquele resultado. Analisando esses números, ressaltamos que a violência para os meninos é aceita como algo natural e, muitas vezes, passa a não ser percebida como tal. Essas diferentes perspectivas advêm da naturalização das manifestações violentas na construção da masculinidade padrão, enquanto que ela é rejeitada na construção da feminilidade referente. Abramovay (2009) menciona que, de acordo com os paradigmas dominantes de masculinidade, mostrar ser forte e potente ainda constitui um traço marcante e valorizado para a representação normalizada de masculinidade. E mais, faz um recorte da violência nos estabelecimentos de ensino afirmando que:

\begin{abstract}
A violência não é vivenciada apenas como atos de agressividade, e sim como 0 modo habitual e cotidiano de relacionamento, de tratamento do outro. Desta forma, o fenômeno passa a ser institucionalizado, comum, banalizado, caracterizando formas de agressão que, muitas vezes, são invisíveis aos olhos da comunidade escolar, mas que, apesar disso, podem ferir profundamente aquele que é vitimado, contribuindo para o surgimento de um sentimento de insegurança e impotência no ambiente escolar (ABRAMOVAY, 2009, p. 4).
\end{abstract}

A invisibilidade e o silenciamento da violência no cotidiano escolar despontaram em conversa informal com a diretora e a coordenadora pedagógica, em que emergiram representações contraditórias acerca da identificação do bullying nos espaços da escola. Enquanto a coordenadora dizia considerar necessário o enfrentamento do tema nas turmas, visto que informava saber de alguns casos que foram confirmados pela instituição, a diretora tentava omiti-los, mencionando que até o momento havia o conhecimento de apenas um registro e que ela considerava uma situação isolada de bullying. A partir dessas falas, entendemos que a escola também é a instituição na qual emergem diferentes discursos, atravessada por diferentes marcadores sociais, culturais e históricos. Todavia, tal posicionamento sugere 0 que Abramovay (2005) chama de banalização da violência. De acordo com as impressões registradas em diário de campo a partir das observações realizadas na escola, isso se verifica, sobretudo, em decorrência da direção escolar não tomar a questão como um problema, mas tratá-la como algo corriqueiro e naturalizado ${ }^{4}$. Ao mesmo tempo, não podemos deixar de registrar que, no decorrer da pesquisa, observamos que os/as professores/as desencadearam o diálogo

4 A Escola fica situada na periferia da cidade e os estudantes são oriundos de uma região irregular, invadida pelas famílias há mais de uma década. Os índices de violência e uso de drogas são altíssimos no bairro. Os/as estudantes deslocam-se até a escola caminhando, e alguns vivem em moradias precárias e sem qualquer saneamento básico. 
acerca do assunto, indicando o enfretamento do fenômeno. Andrade (2007) evidencia que o diálogo, a criação de pactos, o apoio e o estabelecimento de elos de confiança e informação são instrumentos eficazes para diminuir a incidência do bullying nas escolas.

\section{AS VÍTIMAS, OS ESPECTADORES E OS AGRESSORES}

Em situações de bullying há distintas posições a serem ocupadas pelos sujeitos envolvidos na ação. Silva (2010) explica que existem três personagens que se destacam: as vítimas, geralmente, apresentam pouca habilidade de socialização, são tímidas ou reservadas e não conseguem reagir aos comportamentos provocadores e agressivos dirigidos contra elas; os/as espectadores/as são aqueles/as que testemunham as ações de agressores contra as vítimas; os/as agressores/as apresentam, desde muito cedo, aversão às normas e não aceitam ser contrariados/as ou frustrados/as.

Ao buscar identificar essas diferentes situações a partir das respostas ao questionário, apontamos que $100 \%$ dos estudantes informaram ter sido vítimas de bullying nas últimas duas semanas, visto que os atos de violência ocorreram de maneira intencional e repetitiva, porém, sem motivo aparente. Quando inquiridos acerca da indicação dos tipos de violência sofridos, identificamos em cada grupo os resultados apresentados (Figura 1). Notamos também que apenas os espectadores afirmaram ter visto agressões físicas e empurrões. Isso ocorre porque são eles que testemunham as agressões e são mais observadores, enquanto que as vítimas não relatam para não ser agredidas novamente.

Figura 1 - Comparação das agressões nas duas últimas semanas

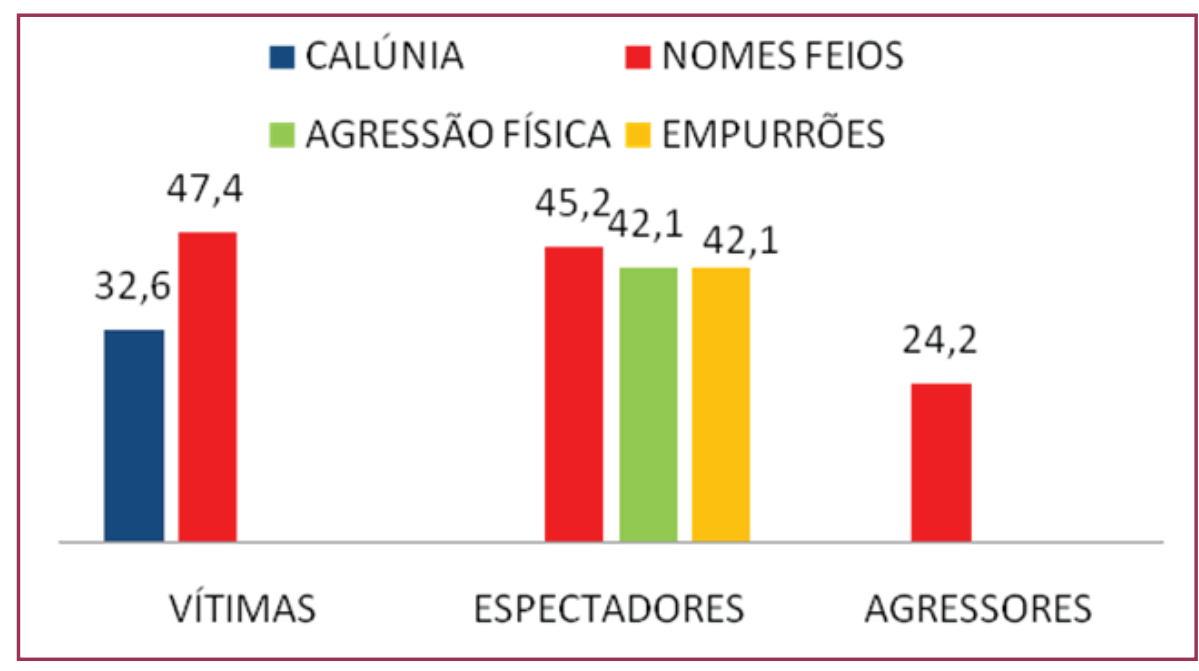

Fonte: Elaborada pelos autores

A representação (Figura 1) mostra que para os agressores ainda é muito difícil se reconhecerem como agressores em um ato de violência, ou admitir já terem agredido alguém, visto que apenas $24,2 \%$ assumiram a posição. Isso ocorre porque alguns agressores/as não consideram o ato como agressão e sim como uma brincadeira. Além disso, os agressores são, em sua maioria, colegas da mesma turma da vítima. Braga e Lisboa (2010) enfatizam que, quando há sofrimento, não se trata mais de uma brincadeira entre amigos. Ao analisarmos o gráfico, percebemos que os espectadores observaram mais situações do que as vítimas 
e os agressores relataram. Grossi e Santos (2009) afirmam que isso acontece porque esses espectadores representam a grande maioria dos/as alunos/as que convivem com a violência e se calam em razão do temor de se tornarem as "próximas vítimas".

Como podemos observar, a forma de bullying que mais se destacou foi a agressão verbal, em que $47,4 \%$ das vítimas foram chamadas por nomes feios. De fato, esse elemento pode ser entendido com o auxílio de Santos (2007), quando diz que os/as alunos/as que são mais visados para serem vítimas são aqueles/as que possuem alguma diferença em relação ao grupo, como obesidade, deficiência física, inteligência acima da média ou dificuldades de aprendizagem. Assim, a característica das vítimas é suficiente para provocar insultos, e, nesse caso, os nomes feios representam o modo mais fácil de humilhar, depreciar e diminuir as vítimas. Esse tipo de agressão ocasiona às vítimas consequências "[...] graves e abrangentes, promovendo no âmbito escolar o desinteresse pela escola, o déficit de concentração e aprendizagem, a queda do rendimento, o absentismo e a evasão escolar" (FANTE, 2005, p. 44).

Por meio de um estudo que tinha como objetivo pesquisar a ocorrência de bullying em adolescentes de três escolas públicas e privadas de Porto Alegre, Bandeira (2009) constatou que o tipo de bullying que predomina contra as vítimas foi o verbal, com $61,1 \%$, caracterizado pelo uso de apelidos, insultos ou deboches. Andrade (2007) afirma que o bullying resume situações em que o/a aluno/a é, com frequência, ameaçado/a, chantageado/a, insultado/a ou simplesmente apelidado/a com algum nome preconceituoso ou que não goste.

Nas conversas informais observamos que os apelidos mais citados para ofender as meninas eram sempre relacionados à aparência, enquanto que para os meninos as ofensas reincidentes insidiam sobre uma suposta homossexualidade. Pereira e Mourão (2005) ressaltam que, desde o nascimento, meninas e meninos são submetidos a um tratamento diferenciado que lhes ensina os comportamentos e emoções adequados e aprovados para o seu sexo. Quando o comportamento parece inadequado em relação ao sexo, começam as piadas e as gozações sobre sexualidade, e os apelidos ofensivos são os primeiros a se destacar. Quanto ao que ofendia meninos e meninas, apontamos que comentários ou apelidos relacionados à aparência ofendiam as meninas porque os cuidados com a apresentação remetem à ideia de uma feminilidade referente, pois a sociedade e a cultura encaminham e esperam que as meninas se preocupem e invistam na sua aparência. Em contraponto, os meninos afirmam a sua masculinidade reafirmando a sua heterossexualidade, por isso as ofensas convergem para a suspeição acerca de uma possível sexualidade desviante. Kimmel (1998, p. 113) assinala que, quando se trata de disputas entre meninos, a "[...] forma de afirmar a masculinidade é através da desvalorização de outras formas de masculinidades, posicionando a hegemônica por oposição ao subalterno, na criação do outro". Assim, também no interior da escola, as construções referentes de masculinidades são utilizadas entre os meninos para questionar e testar através de violências físicas e morais suas virilidades (JUNQUEIRA, 2009).

Assim, não há surpresa quando as fontes de pesquisa apontam que os meninos são, em sua grande maioria, os agressores. Mazzon (2009) chama a atenção para o fato de que os meninos apresentam atitudes mais preconceituosas que as meninas em relação à identidade de gênero, o que permite entender o maior número de agressores do sexo masculino, uma vez que essa questão é reincidente nas práticas de bullying. Para Lopes Neto (2005), também há um predomínio de agressores do sexo masculino, enquanto que, no papel de vítima, não há diferenças entre os sexos. Menegotto, Pasini e Levandowski (2013) analisaram artigos 
científicos sobre bullying escolar, em periódicos nacionais, entre os anos de 2009 e 2011, e identificaram que a grande maioria dos agressores é do sexo masculino e pratica a violência por meio de agressões físicas e intimidações. As meninas costumam praticar a violência por meio de boatos maldosos, exclusões do grupo, entre outros. Nosso estudo apontou a predominância do sexo masculino tanto no papel de agressor como no de vítima, ou seja, de acordo com as vítimas, $46,3 \%$ são alvo de agressores do sexo masculino, 28,4\% são do sexo feminino e $25,3 \%$ afirmaram não sofrer agressões. Já os/as agressores/as apontaram que $41,05 \%$ das pessoas agredidas eram do sexo masculino, 22,1\% do sexo feminino, e 27,3\% indicaram que não agrediam seus colegas.

Diante desse cenário, as observações e as conversas informais com a equipe diretiva da escola sugerem que os meninos praticam mais o bullying pelo fato de não manifestarem receio de serem repreendidos e/ou responsabilizados pela família. A mesma coisa não aconteceu com as meninas que se envolveram em práticas de bullying, visto que um número maior delas sofreu represálias familiares em função dos comportamentos violentos, recebendo, ainda, apoio de pais, amigos e da escola para mudarem suas ações. Entendese, com isso, que elas quebraram as regras ao agredir alguém e que os meninos não foram castigados, pois se estabeleceu uma naturalidade em relação ao comportamento agressivo dos meninos, o que não acontece da mesma forma com as meninas. Vianna e Finco (2009) completam que o que é valorizado para a menina não é, muitas vezes, apreciado para os meninos, e vice-versa. Os autores destacam ainda que se, por um lado, é possível observar o controle da agressividade na menina, por outro lado o menino sofre processo semelhante, em que neles são bloqueadas expressões de sentimentos como ternura, sensibilidade e carinho. Diante disso, a escola está sendo cada vez mais requisitada para trabalhar com a diversidade, promovendo a educação das diferentes masculinidades e feminilidades, mostrando que elas podem ser vividas no plural.

\section{TERRITÓRIO DAS AÇÕES}

A escola possibilita que meninos e meninas desfrutem de vários espaços de socialização, em que meninos e meninas criam também o território no qual as ações de bullying são verificadas e se entrelaçam as questões de gênero. Stramann (2005) diz que os espaços escolares devem ser interpretados como um lugar para movimentar-se, onde o movimento é visto como um princípio geral na organização e configuração da escola.

De fato, nem todas as crianças têm liberdade na escola para usar todo e qualquer lugar. A quadra esportiva é um exemplo de espaço predominantemente ocupado pelos meninos. Por outro lado, nas rodas de conversas que observamos nas esquinas da escola participam poucos meninos. Pereira e Mourão (2005) corroboram essa ideia quando afirmam que a escola cotidianamente produz e reproduz ações que separam e demarcam o que é considerado socialmente pertencente ao mundo feminino e ao mundo masculino. Tal afirmação foi percebida quando notamos que meninos e meninas até podem brincar no mesmo espaço, porém de maneiras diferentes, ou seja, as meninas dificilmente foram vistas com uma bola de futebol, mesmo demonstrando interesse no jogo. Da mesma maneira, os meninos não demonstraram interesse na prática do voleibol, uma vez que culturalmente esse é um esporte sugerido às meninas. Em entrevista com estudantes, esses relataram que se um menino jogar voleibol com 
as meninas poderia ser motivo de zombaria praticada pelos outros colegas e, possivelmente, questionariam a sua sexualidade. Assim, as meninas desfrutavam o recreio escolar buscando o mínimo de interação com os meninos. As mais novas, geralmente, pulavam corda enquanto que as meninas mais velhas se reuniam em rodas de conversa, enquanto que os meninos ocupavam as quadras esportivas.

O modo como meninos e meninas se movimentam é também refletido nas práticas do bullying. Assim, ao fazer um mapeamento dos locais de destaque onde o fenômeno acontece dentro da escola, verificamos que para as vítimas e espectadores o recreio escolar é o local mais propenso. Já os/as alunos/as que agrediram alguém apontaram a sala de aula como 0 lugar mais fácil para a prática do bullying, como podemos verificar na Figura 2:

Figura 2 - Quanto ao local das agressões

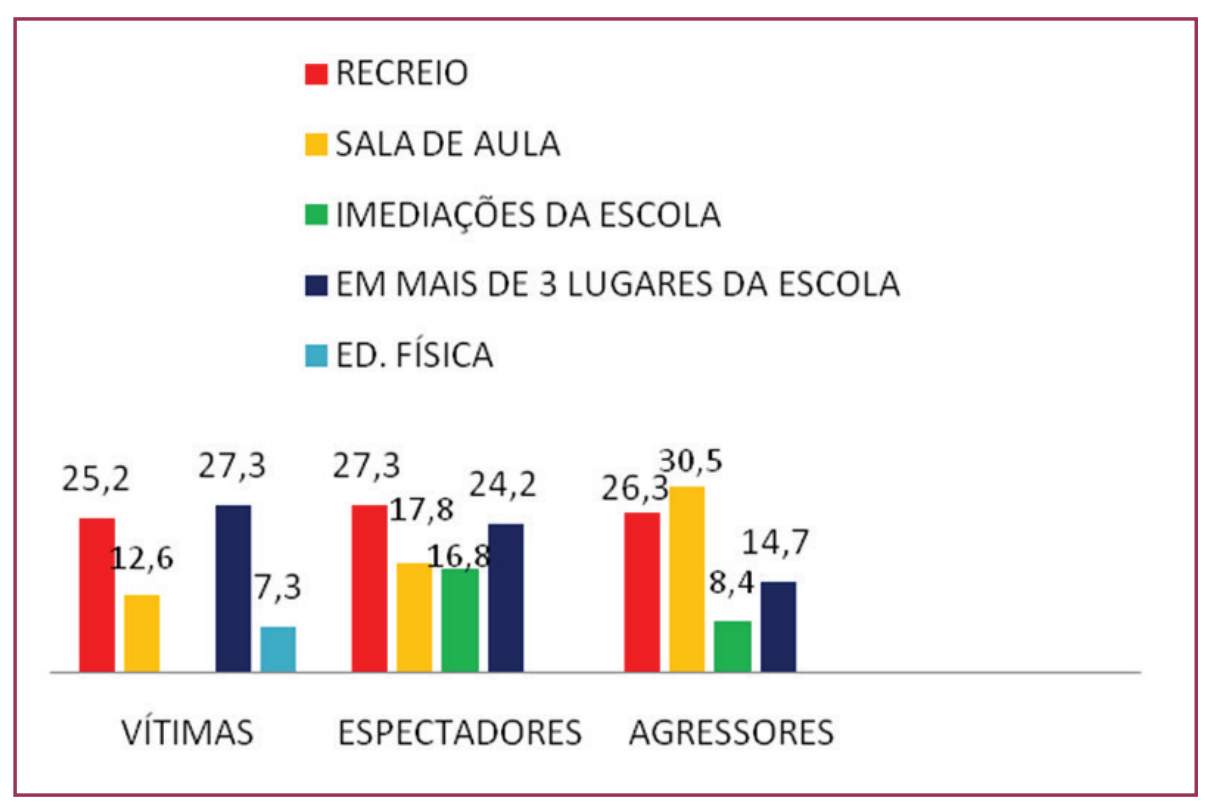

Fonte: Elaborada pelos autores

De acordo com Wenetz e Stigger (2007, p.9), as análises sublinham que tanto na escola quanto no recreio:

[...] as crianças não são tão livres, não brincam todas juntas, não fazem sempre o que querem, nem todas brincam em todos os espaços e, ainda, nem todas brincam do que gostariam.

O que se observa é que essas ações são orientadas por uma construção:

[...]cultural particular dentro do contexto escolar e do recreio com algumas características próprias, as quais demandam [...] uma negociação que inclui a maneira de lidar com os espaços conforme gênero e geração.

Ainda afirmam que não existe regra explícita que diga que as meninas não podem utilizar os espaços das quadras, mas, de certo modo, os meninos se apropriam e legitimam a quadra como um espaço próprio para um jogo masculino. Esse é mais um exemplo de conflito que, quando se tornam rotineiros na escola, tendem a se transformar em bullying, pois de maneira repetida alguns se divertem à custa de outros que sofrem. Como consequência, surgem as vítimas, os/as agressores/as e aqueles/as que participam indiretamente da ação 
do/a agressor/a, ou seja, os/as espectadores/as da agressão. Ressaltamos, portanto, que o recreio se apresentou como o local de maior número de práticas de vitimação, tanto com agressões às meninas quanto aos meninos. De acordo com as vítimas, identificamos que a sala de aula $(12,6 \%)$ foi o segundo local mais propício às agressões; em terceiro lugar aparecem os espaços destinados à Educação Física (7,3\%); ainda 6,4\% foram agredidos na rua ou imediações da escola, e 5,2\% foram agredidos em corredores e escadas. Também destacamos que $27,3 \%$ das vítimas afirmaram que essas agressões se repetem em mais de um local na escola. Embora nenhum espectador, tampouco o agressor, tenha presenciado ou assumido praticá-lo na disciplina, as vítimas apontaram que para 7,3\% houve bullying nas aulas de Educação Física - isso corrobora o estudo de Linhares, Faria e Lins (2013), que abordou a diferença do bullying escolar entre meninos e meninas -, e em torno de $20 \%$ dos estudantes afirmaram que a Educação Física é um espaço de práticas de bullying.

Segundo as nossas fontes de pesquisa, e, especificamente, os espectadores, a incidência maior foi no recreio $(27,3 \%)$, seguido da sala de aula $(17,8 \%)$, na rua ou imediações da escola $(16,8 \%)$, em corredores e escadas $(5,2 \%)$, e um percentual considerável $(24,2 \%)$ afirmou presenciar agressões em mais de um desses locais. Por outro lado, os/as alunos/as agressores/as apontaram que 30,5\% das suas ações ocorrem diante dos/as professores/as, ou seja, em sala de aula. Em relação a isso, Grossi e Santos (2009) chamam a atenção para o fato de que a agressão em sala de aula procede, visto que a sala de aula se configura no espaço de maior intimidade do grupo, e, por isso, é mais propenso ao reconhecimento das diferenças entre as pessoas.

Sobre o comportamento agressivo tanto no recreio como em sala de aula, Braga e Lisboa (2010) afirmam que por muito tempo pais e professores admitiram o comportamento agressivo como algo natural e normativo que ocorria nas escolas, porque o confundiam com brincadeiras. Levando em consideração tais aspectos, sobre os pátios escolares, Fernandes e Elali (2008) dizem que um número excessivamente grande de alunos pode produzir agressividade e irritabilidade, e, por outro lado, um número muito reduzido pode gerar isolamento e pouca socialização. Em suma, chamamos a atenção dos professores para que olhem com cuidado para o recreio escolar, uma vez que nele são acordadas negociações entre os estudantes, as quais organizam a ocupação dos espaços escolares de modo desigual, gerando exclusão, preconceito e descontentamento.

\section{CONSIDERAÇÕES FINAIS}

Os resultados mostraram que o sexo masculino se sobressai diante do sexo feminino nos casos que envolvem esse fenômeno. Isso significa que os meninos se destacam como agressores e como vítimas, e ainda que utilizam mais a força física para intimidar as suas vítimas, enquanto que as meninas utilizam mais a agressão verbal. Essas diferenças nos modos de agir são produzidas em meio ao processo de generificação dos corpos que acontece em diferentes instâncias sociais, entre as quais a escola. Revelou-se também que em quase todos os espaços da escola acontecem práticas de bullying, porém, o local de maior incidência se concentra no período do recreio escolar. Portanto, todos os envolvidos precisam problematizar 0 assunto na escola, com o intuito de prevenir comportamentos agressivos em quaisquer espaços, sejam eles salas de aula, refeitórios, banheiros, quadras esportivas etc. 
Além disso, a escola tende a reforçar normas e padrões a serem seguidos por meninas e meninos, de acordo com os papéis normalizados para cada sexo, e que tendem, muitas vezes, a incentivar preconceitos na escola. A atuação de professores e professoras junto à equipe diretiva (coordenação e direção) se faz necessária para que de forma conjunta eles e elas possam atuar de maneira efetiva nas situações envolvendo as relações de gênero. Podemos pensar, desse modo, em uma educação voltada para a diversidade. Enfim, buscamos uma sociedade menos desigual, em que as diferenças biológicas, por exemplo, não sejam utilizadas para justificar as diferenças entre homens e mulheres e perpetuar a violência entre eles e elas.

\section{REFERÊNCIAS}

ABRAMOVAY, Miriam. Proposta pedagógica: Debate: violência, mediação e convivência na escola. Boletim Ministério da Educação, Brasília, n. 23, nov. 2005.

ABRAMOVAY, Miriam; CUNHA, Anna Lucia; CALAF, Priscila Pinto. Revelando tramas, descobrindo segredos: violência e convivência nas escolas. Brasília: Rede de Informação Tecnológica Latino Americana, 2009.

ALVARENGA, Luiz Fernando Calage; DAL IGNA, Maria Cláudia. Corpo e sexualidade na escola: as possibilidades estão esgotadas? In: MEYER, Dagmar Estermann; SOARES, Rosângela de Fátima Rodrigues. (Org.). Corpo, gênero e sexualidade. Porto Alegre: Mediação, 2004. p.62-72.

ANDRADE, Michela Pereira. Bullying: concepções dos autores envolvidos. 2007. Monografia (Conclusão de Curso) - Faculdade de Ciências, Universidade Estadual Paulista, Bauru, 2007.

BANDEIRA, Claudia de Moraes. Bullying: auto estima e diferenças de gênero. 2009. 67 f. Dissertação (Mestrado) - Instituto de Psicologia, Universidade Federal do Rio Grande do Sul, Porto Alegre, 2009.

BONFIM, Daiane Lopes et al. Ocorrência de bullying nas aulas de educação física em uma escola do Distrito Federal. Pensar a Prática, Goiânia, v. 15, n. 2, p. 302-317, abr./jun. 2012.

BRAGA, Luisa de Lima; LISBOA, Carolina. Estratégias e coping para lidar com o processo de Bullying: um estudo qualitativo. Revista Interamericana de Psicologia, Porto Alegre, v. 44, n. 2 , p. 321-331, 2010.

CERVO, Amado Luiz; BERVIAN, Pedro Alcino. Metodologia científica. 5. ed. São Paulo: Pearson Prentice Hall, 2002.

DEVIDE, Fabiano Pries. Gênero, mulheres e esporte: história das mulheres nos jogos olímpicos modernos. ljuí: Unijuí. 2005.

FACCO, Lúcia. Construção de comportamentos homofóbicos no cotidiano da educação infantil. In: JUNQUEIRA, Rogério Diniz. (Org.). Diversidade sexual na educação: problematizações sobre a homofobia nas escolas. Brasília: Ministério da Educação, Secretaria de Educação Continuada, Alfabetização e Diversidade, UNESCO, 2009. p. 141-158.

FANTE, Cleo. Fenômeno bullying: como prevenir a violência nas escolas e educar para a paz. 2. ed. Campinas, SP: Verus, 2005.

FELIPE, Jane; GUIZZO, Bianca S. Entre batons, esmaltes e fantasias. In: MEYER, Dagmar 
Estermann; SOARES, Rosangela de Fátima Rodrigues. (Org.). Corpo, gênero e sexualidade. Porto Alegre: Mediação, 2004. p. 31-40.

FERNANDES, Odara de Sá; ELALI, Gleice Azambuja. Reflexões sobre o comportamento infantil em um pátio escolar: o que aprendemos observando as atividades das crianças. 2008. Paidéia, Ribeirão Preto, v. 18, n. 39, p. 41-52, 2008.

FRANSCISCO, Marcos Vinicius; LIBÓRIO, Renata Maria Coimbra. Um estudo sobre o bullying entre escolares do ensino fundamental. Psicologia: reflexão e crítica, São Paulo, v. 22, n. 2, p. 200-207, 2009.

FREIRE, Isabel P., SIMÃO, Ana M. Veiga; FERREIRA, Ana S. O estudo da violência entre pares no $3^{\circ}$ ciclo do ensino básico - um questionário aferido para a população escolar portuguesa.

Revista Portuguesa de Educação, Braga, v. 19, n. 2, p. 157-183, 2006.

GOELLNER, Silvana Vilodre. Mulher e esporte no Brasil: entre incentivos e interdições elas fazem história. Pensar a Prática, Goiânia, v. 8, n. 1, p. 85-100, 2005.

GOELLNER, Silvana Vilodre; FIGUEIRA, Marcia Luiza Machado; JAEGER, Angelita Alice. A educação dos corpos, das sexualidades e dos gêneros no espaço da educação física escolar. In: SILVA, Fabiane Ferreira da et al. (Org.). Sexualidade e escola: compartilhando saberes e experiências. 2. ed. rev. e ampl. Rio Grande: FURG, 2008. p. 90-102.

GROSSI, Patrícia Krieger; SANTOS, Andréia Mendes dos. Desvendando o fenômeno bullying nas escolas públicas de Porto Alegre, RS, Brazil. Revista Portuguesa de Educação, Braga, v. 22, n. 2, p. 249-267, 2009.

JUNQUEIRA, Rogério Diniz. (Org.). Diversidade sexual na educação: problematizações sobre a homofobia nas escolas. Brasília: Ministério da Educação, Secretaria de Educação Continuada, Alfabetização e Diversidade, UNESCO, 2009.

KIMMEL, Michael. A produção simultânea de masculinidades hegemônicas e subalternas. Horizontes Antropológicos, Porto Alegre, v. 4, n. 9, p. 103-117, out. 1998.

LINHARES, Riana Duarte; FARIA, João Paulo Oliveira; LINS, Raquel Guimarães. O bullying na educação física escolar e sua diferença entre meninos e meninas. Pensar a Prática, Goiânia, v. 16, n. 2, p. 484-500, abr./jun. 2013.

LOPES NETO, Aramis A. Bullying: comportamento agressivo entre estudantes. Jornal de Pediatria, Rio de Janeiro, v. 81, 5 Supl, p. S164-S172, 2005.

LOURO, Guacira Lopes. Pedagogias da sexualidade. In: LOURO, Guacira Lopes (Org.) 0 corpo educado: pedagogias da sexualidade. Belo Horizonte: Autêntica, 2010a. p. 4-24.

LOURO, Guacira Lopes. Gênero, sexualidade e educação: uma perspectiva pós-estruturalista. Petrópolis: Vozes, 2010b.

MAZZON, José Afonso. Projeto de estudo sobre ações discriminatórias no âmbito escolar, organizadas de acordo com áreas temáticas, a saber, étnico-racial, gênero, geracional, territorial, necessidades especiais, socioeconômica e orientação sexual: relatório analítico final. São Paulo: Fundação Instituto de Pesquisas Econômicas, 2009.

MENEGOTTO, Lisiane Machado de Oliveira; PASINI, Audri Inês; LEVANDOWSKI, Gabriel. 
prática, São Paulo, v. 15, n. 2, p. 203-215, maio/ago. 2013.

MEYER, Dagmar Estermann. Gênero e Educação: teoria e política. In: LOURO, Guacira Lopes; FELIPE, Jane; GOELLNER, Silvana Vilodre (Orgs). Corpo, gênero e sexualidade: um debate contemporâneo. 9.ed. Petrópolis, RJ: Vozes, 2013. p. 9-27.

MINAYO, Maria Cecília de Souza; SANCHES, Odécio. Quantitativo-qualitativo: oposição ou complementaridade? Caderno de Saúde Pública, Rio de Janeiro, v. 9, n. 3, p. 239-262, jul./set. 1993.

PEREIRA, Beatriz O. et al. O bullying nas escolas portuguesas: análises de variáveis fundamentais para a identificação do problema. In: CONGRESSO GALAICO-PORTUGUÊS DE PSICOPEDAGOGIA, 2. 1996. [Actas...] Braga: Universidade do Minho, 1996. v. 1, p. 71-81.

PEREIRA, Sissi Aparecida Martins; MOURÃO, Ludmila. Identificações de gênero: jogando e brincando em universos divididos. Motriz, Rio Claro, v. 11, n. 3, p. 205-210, set./dez. 2005.

SANTOS, Luciana Pavan Ribeiro. 0 papel do professor diante do bullying na sala de aula. 2007. Trabalho de Conclusão de Curso (Pedagogia). - Universidade Estadual Paulista "Julio de Mesquita Filho", 2007.

SILVA, Rosimeri A. O ponto fora da curva. In: MEYER, Dagmar Estermann; SOARES, Rosângela de Fátima Rodrigues. (Org.). Corpo, gênero e sexualidade. Porto Alegre: Mediação, 2004. p. $125-133$.

SILVA, Ana Beatriz Barbosa. Bullying: mentes perigosas nas escolas. Rio de Janeiro: Objetiva, 2010.

STAKE, Robert E. Pesquisa qualitativa: estudando como as coisas funcionam. Tradução de Karla Reis; revisão técnica de Nilda Jacks. Porto Alegre: Penso, 2011.

STRAMANN, Reiner Hildebrandt. Escola(s) em movimento. Movimento, Porto Alegre, v. 11, n. 1, p. 121-139, jan./abr. 2005.

VIANNA, Claudia; FINCO, Daniela. Meninas e meninos na Educação infantil: uma questão de gênero e poder. Cadernos Pagu, São Paulo, n. 33, p. 265-283, jul./dez. 2009.

WENETZ, Ileana; STIGGER, Marco Paulo. A construção do gênero no espaço escolar. Movimento, Porto Alegre, v. 12, n. 1, p. 59-80, jan./ abr. 2006.

WENETZ, Ileana; STIGGER, Marco Paulo. Gênero e recreio: um espaço educativo? In: CONGRESSO BRASILEIRO DE CIÊNCIAS DO ESPORTE, 15. e CONGRESSO INTERNACIONAL DE CIÊNCIAS DO ESPORTE, 2., 2007. [Anais...] Disponível em: < http:// www.cbce.org.br/docs/cd/lista_area_03.htm>. Acesso em: 4 fev. 2012.

WENETZ, lleana; STIGGER, Marco Paulo; MEYER, Dagmar Estermann. As (des) construções de gênero e sexualidade no recreio escolar. Revista Brasileira de Educação Física e Esporte, São Paulo, v. 27, n. 1, p. 117-128, jan./mar.2013. 